\title{
The Usability of BenKids Mobile Learning App in Vocabulary Teaching for Preschool
}

\author{
https://doi.org/10.3991/ijim.v15i24.22237 \\ Saria Eltalhi*(ه) ${ }^{(}$, Huda Kutrani*, Reem Imsallim, Mikal Elrfadi \\ University of Benghazi, Benghazi, Libya \\ Saria.eltahi@uob.edu.ly
}

\begin{abstract}
Learning mobile applications (apps) have become highly popular and are widely used. However, they will only be accepted by users if their usability is of an acceptable level. Usability testing and measuring the level of knowledge are assisting the support of the benefits of such applications. The "BenKids" app has been designed especially for preschool children (aged three to five) to learn English as a second language. It was created for android devices to teach vocabulary to preschool children by providing the user with a straightforward interface. This study aimed to assess knowledge gain and the usability test of the "BenKids" mobile app among preschool children. The children's knowledge level was assessed by pre-test and post-test between the experimental and control groups. While the usability of the "BenKids" app was measured with the experimental group, both groups had to perform the same three tasks. The results showed that the experimental group had increased their knowledge level compared with the control group. Although children faced difficulties with some procedures, the usability test was generally good.
\end{abstract}

Keywords - usability testing, mobile learning, mobile apps

\section{$1 \quad$ Introduction}

Electronic devices, like mobiles, are prominently used by people of all ages [1]. Mobile devices are very prominent in the lives of children, and mobile devices ownership among children aged 4-14 has been growing since 2005 [2][3]. Learning activities offered by mobile apps increase children's interest during the learning process [4]. This has led to the widespread of Mobile learning (M-learning), which makes use of smartphones and tablets in education to create learning materials and learning aids [1][5]. An advantage of M-learning is that learners can gain continuous access to learning content regardless of time or place. Due to mobile learning being fun and entertaining for learners, the number of schools and teaching institutes using M-learning has increased [2][3][5]. Therefore, mobile learning inside and outside of the classroom environment has gained ground as an alternative way of providing learning for students [6].

*Saria and Huda contributed equally to this manuscript and should be considered as joint first authors. 
This research is organized as follows. Section 2 introduces a brief on mobile learning app. and the usability tests to context the research problem and objectives. Section 3 explains the material and methods that were used for this research. Finally, the research concludes with a discussion and a conclusion regarding the findings.

\section{Literature review}

In Libya, using mobile learning is limited. Although preschool children use their parents' mobile devices or have their tablets, they use them for playing games. This presents a problem, especially during Covid-19 lockdown, where children spend extended playing games instead of usefully using mobile devices. Therefore, this research focuses on measuring the level of knowledge after using the "BenKids" mobile app (for learning English as a second language) and assessing the usability. All of this supports the benefits of such an application; thus, that will encourage kindergarten teachers to use the mobile learning application, especially as it is considered a solution to child education during the Covid-19 pandemic.

\subsection{Mobile devices and preschool education}

Development in mobile devices encourages children to use them increasingly and spend more time playing and learning [5][6]. Additionally, smart device mobility and ease allow children to learn in various settings instead of traditional desks and chairs [7]. Those features permit children with extended flexibility, such as laying the tablet in their lap, on the floor, or moving with it to any area within their home [8].

Kalogiannakis \& Papadakis (2019) reported no relationship between information communication technology skills and students' use of mobile learning. Also, they recommended the development of a strategy for using mobile education starting from preschool education [6]; especially, preschool children do not need to develop the manual handling skills to use a separate keyboard and mouse required by general-purpose computers in order to gain access to interactive content explicitly designed for them [9].

Many studies indicated that some characteristics of mobile devices, such as moving an object by touching a point on the screen and the automatic screen rotation, encourage preschool children to use such devices, especially that preschool children may face difficulties finishing an activity using the mouse. Moreover, researchers indicated that using digital education applications provides children with new ways to express themselves, supporting their cognitive, language, and socio-emotional development. [1][3] [5][7][10].

In this context, digital education applications can become promising tools for efficient and practical learning, especially in preschool education. These tools allow children to take advantage of new learning platforms and effectively reach new knowledge through activities related to their immediate interests and real-life scenarios in learning domains, such as mathematics [10][11]. 
Recently, many studies indicted the benefits of using ICT and digital education applications in young children's education. Liu \& Hwang (2020) reported that students' enthusiastic reactions to these new media. Students were eager to participate in learning activities due to the medium's novelty, visual characteristics, and ease of use. The attractive appearance and the innovative touch interface are considered key learning facilitators for young children [9]. Also, Papadakis et al. (2021) reported that digital technologies could positively improve early mathematics skills. The use of mobile technologies in mathematics education can encourage meaningful student engagement with mathematics by embedding the subject in authentic contexts [11]. Moreover, Shuler (2012) found that the number of educational apps that targeted preschool and primary school-age children increased to $72 \%$ from $47 \%$ in 2009 [12].

\section{2 "BenKids" application}

"BenKids" is an application designed especially for preschool children aged from three to five. This application was intended to support young children in learning English as a second language. The "BenKids" application had been developed by Aisha Nori Idres and Saria Eltalhi in 2019; Permission was granted from the developers to use the application in this study. A detailed description of the "BenKids" application is explained by Aisha et al. [13]. The application presents vocabulary items of alphabets, numbers, animals, and objects. The alphabet consists of 26 items, numbers consist of 10 items, animals consist of 12 items, and objects consist of 19 items. Animals and objects are presented in the application through songs; they also accompany numbers to clarify number sense and accompany each letter to illustrate beginning sounds.

The researchers designed the homepage, divided into four critical sections: vocabulary, handwriting, games, and songs. The screenshot of the homepage is presented in Figure 1. The vocabulary section on the top contains the alphabet, numbers, animals, and colors. The Alphabet section will provide letters with the picture related to the letter. The letter "A" appears with a picture of an apple above and the word "apple" below.

To further assist children learning with speaking skills, the sound feature was included within the apps. It is possible to press the repeat button to listen to the pronunciation or press the left arrow and advance to the subsequent alphabet. The number tab leads to numbers. Each time Child press it, a number appears with a matching picture and pronunciation. The child can repeat or move to the following number in the same way. The animal tab reveals animals through pictures, words, and pronunciation. 


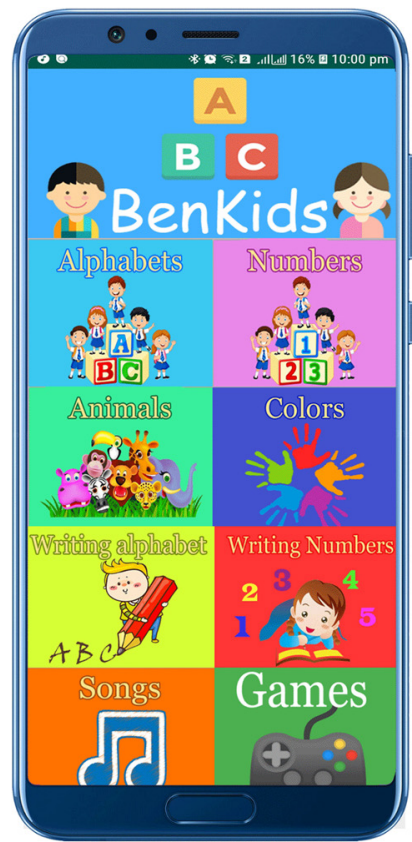

Fig. 1. The homepage in the BenKids

Write Section allows the children to write practice. It contains an alphabet and Numbers tab. When an alphabet appears, the children can trace it, press erases, or trace the next alphabet. The numbers tab works in the same way. The game section contains the memory game and a questions game. They concern vocabulary in the previous two sections. This game requires the child to match a letter from the alphabet to an object picture beginning with the same letter. This game helps the child to remember the information when one fact or item connects to another. The songs section contains four songs. They concern vocabulary in the previous sections. These songs make children engage in a new and exciting way to entertain and teach them simultaneously. They concern vocabulary in the previous sections.

\subsection{The usability tests}

Although some mobile learning apps can provide a good learning experience for preschool children, most 'educational' apps do not provide significant evidence to substantiate that [14][15]. Taibah (2016) pointed out that it is vital to conduct usability tests on educational apps designed to be used in education [15]. Also, Papadakis et al. (2020) reported that usability was one of the four main dimensions that help to assess educational apps for children aged 3-6 years [14].

In general, usability refers to how easily software can be learned and understood [16]. Although the measurement of learning outcomes is a complex case, the easy-to-use aspects are more pronounced and are straightforwardly evaluated. Learning apps with 
a good and accessible design could offer practical support for children to learn and promote knowledge or skill acquisition through repetitive practice [14][17].

Moreover, usability assists in ensuring better software quality, ease of use, and appeal to users. In addition, usability tests provide an insight into the ease of mobile app use by testing the app with a sample of actual users [3][17]. Usability testing can present challenges, especially with children aged three to five years, because they cannot understand what is being asked or express their answers correctly [3][17]. In such tests, users are given commands by a researcher to perform while being observed to note whether they face any problems or confusion. By using such tests, apps and software can be enhanced to guarantee a smoother user experience and increase their appeal to children [3][15][17]. Also, the usability of educational software for children can be elevated [15].

After the post-test, many studies have shown that students' knowledge scores indicated that mobile learning could increase learning motivation. Also, the findings enhanced the excellent usability of applications, such as ease of use and appeal to users [18][19][20].

Based on the results of several studies, the usability study can be considered a multistage problem-solving process. It analyses and expects how the children use an educational application and assess their knowledge gain. Moreover, it can assist developers in obtaining the actual first-time users' intuition of their design experience [3][15][17]. Some usability tests measure aspects like the visibility of the system status, the match between the system and the real world, and user control and freedom. This match can be used in determining educational application usability [3][16]. These would assist developers in improving the application.

Many mobile learning apps. Focus on colorful and attractive interfaces to children, but the usability of such applications is given little care. In addition, adopting mobile learning will be easier if kindergarten teachers believe the mobile learning application could increase students' knowledge. This study aims to assess knowledge gain and the usability test of the "BenKids" mobile app among preschool children and assist developers in improving the application.

\section{$3 \quad$ Material and methods}

An Experimental study was conducted in a quiet and comfortable room at Daar Alallam preschool in Benghazi. as shown in Figure 2. The Daar Alallam preschool is one of the preschools that teach the English Language as a second language.
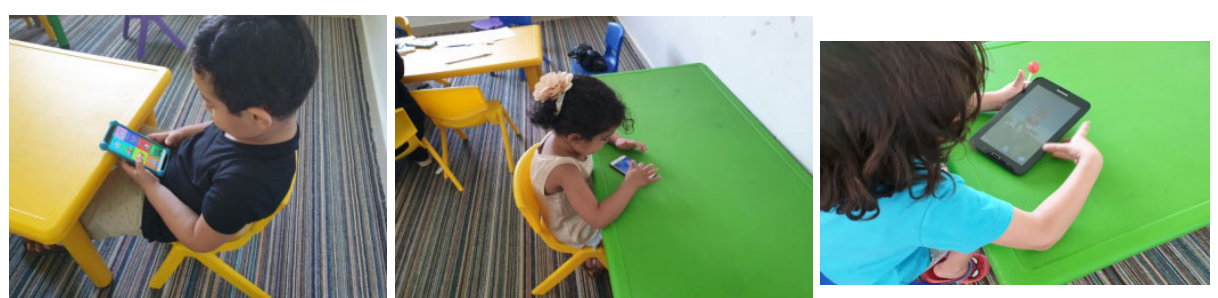

Fig. 2. Usability testing with preschool children 


\subsection{Study participants}

In this study, the researchers selected 20 children from Daar Alallam preschool and used its facilities to collect data (Figure 2). The children were aged from three to five years and were selected randomly. The children were divided into two groups, the experimental group and the control group. The study was conducted from 18th February 2019 to 22nd April 2019 (45 days). Forty-five classes (one hour per class) were taught to learn the English Language by the "BenKids" app using mobile devices for the experimental group, while a preschool teacher taught the control group the English Language.

Consent: The researchers explained the goal of the application to parents and how it worked. The parents signed a consent form allowing their children to participate in the experiment and agree to the publication of this manuscript.

\subsection{Experimental design}

The researchers prepared scenarios for running the test and divided it into three phases: pre-test, post-test, and usability test.

First phase: pre-test. The pre-test was used to assess the extent of children's vocabulary knowledge before using the "BenKids" application. All children who were selected did a pre-test. The children's vocabulary knowledge of the alphabet, numbers, animals, and objects was assessed using flashcards in the pre-test. One of the researchers would hold up the card, and the child would supply the item's name on that card.

Question: What is that?

Answer: Name of the picture on flashcard in English.

Final scores for the pre-test were calculated by giving one point for each correct answer and giving a zero point for any incorrect answer. The total score was 67 marks allocated to the different vocabulary items: 26 marks for alphabets, ten marks for numbers, 12 marks for animals, and 19 marks for objects. The assessment score of knowledge level for pre-test is presented in Table 1. Based on the children's results, a Matching Technique was used to divide the participating children into the control and experimental groups. The approach aimed to balance the distribution of children's knowledge levels in both groups. The children who had a high level of knowledge were distributed equally between the experimental and control groups; Moreover, the children with moderate and low levels of knowledge were likewise divided equally between the two groups.

Final samples: The experimental group was ten children, and the control group was ten children. 
Table 1. Assessment scores of pre-test and post-test

\begin{tabular}{|l|c|c|c|c|c|}
\hline $\begin{array}{c}\text { Mean of Knowledge } \\
\text { Level }\end{array}$ & $\begin{array}{c}\text { Overall } \\
\text { Score }\end{array}$ & $\begin{array}{c}\text { Alphabet } \\
\text { (Total } \\
\text { score=26) }\end{array}$ & $\begin{array}{c}\text { Number } \\
\text { (Total } \\
\text { score=10) }\end{array}$ & $\begin{array}{c}\text { Animals } \\
\text { (Total } \\
\text { score=12) }\end{array}$ & $\begin{array}{c}\text { Objects } \\
\text { (Total } \\
\text { score=19) }\end{array}$ \\
\hline $\begin{array}{l}\text { High level } \\
(75 \%-100 \%)\end{array}$ & $50-67$ & $20-26$ & $8-10$ & $10-12$ & $15-19$ \\
\hline $\begin{array}{l}\text { Moderate level } \\
(51 \%-74.9 \%)\end{array}$ & $34-49$ & $14-19$ & $6-7$ & $7-9$ & $10-14$ \\
\hline Low level $(0-50 \%)$ & $0-33$ & $0-13$ & $0-5$ & $0-6$ & $0-9$ \\
\hline
\end{tabular}

Second phase: post-test. The researchers installed the "BenKids" application on the smartphones and tablets of the experimental group, while a preschool teacher taught the control group the vocabulary items. Each group was given an hour-long session every day.

The post-test was used to assess the extent of children's knowledge of the vocabulary items after using the "BenKids" application for the experimental group. The procedures for the post-test were identical to those for the pre-test.

Question: What is that?

Answer: Name of the picture on flashcard in English.

The final scores for the post-test were calculated in the same manner as the scores of the pre-test. One point was given to each correct answer and a zero point for each incorrect answer.

The total score was 67 divided: 26 marks for alphabets, ten marks for numbers, 12 marks for animals, and 19 for objects. The assessment score of knowledge level for post-test is presented in Table 1.

Third phase: The usability test. The usability test phase collected data from the experimental group regarding the "BenKids" application. Data collection was carried out through observation and evaluation.

Usability heuristics. One-to-one sessions were conducted with each child to identify their level of understanding while using the "BenKids" application. The researchers observed the children record their behavior. The observation checklist used in this research was based on Jakob Nielsen's 10 Usability Heuristics Principles (1995). The checklist was utilized to identify the children's motivational behavior challenges and note the efficiency of the application while the children were using it [21]. Four usability heuristics were selected based on the significant components suitable for kids' educational application evaluation. Usability Heuristics used a 5-points rating (1 bad to 5 good) to assess. The average was calculated for each item of the questionnaire. The average from 1 to 2.59 means "bad,"; whereas the average from 2.6 to 5 means "good."

Assessment of efficiency of the "BenKids" application. Assessment of efficiency of the "BenKids" application was based on three tasks. The researchers asked children to perform three tasks on the "BenKids" application. Each task consisted of two to three procedures. The child needed to finish all procedures while the observer record one of the notes (Complete (C), Incomplete (I), Complete with help $(\mathrm{CH})$, and Complete with Hints/Guide (CG)) for each procedure. For example, Task 1 included 1) Open the application and go to Alphabets from the main menu. 2) How can you get the alphabet sound? Or how can you repeat the sound? 3) Go back to the main screen/home. Each 
child was given five minutes to freely explore the "BenKids" application before completing the tasks.

\section{Data analysis}

Data analysis was executed using the SPSS program (Statistical Package for Social Sciences) version 20. Mean, distribution table, cross-tabulation, and column charts were used to describe and compare pre-test and post-test usability. The paired t-test was used to compare the children's knowledge in both the pre-test and post-test. The $\mathrm{t}$-test was used for the usability test. The level of significance was set at $5 \%(\mathrm{p}<0.05)$.

\section{$5 \quad$ Results}

The sample involved 20 preschool children, 14 boys, and six girls, aged three and five years. All the children never had an English learning experience before this study. Most of the children did have experience using mobile devices. Therefore, the children did not need special training when they were first given the "BenKids" application.

\subsection{Knowledge gain}

The results of the paired t-test analysis and scores of the children in the pre-testing and post-testing can be seen in Table 2. In the pre-test, both the control and the experimental groups had the same knowledge level in each item (alphabets, numbers, animals, and objects). There were no significant mean differences between children's scores in the two groups ( $\mathrm{P}>0.05$ for each item). However, according to assessment scores in Table 1, both the control and the experimental groups had a low level of English knowledge in alphabets, numbers, animals, and objects. In the post-test, there were significant mean differences between children's scores in both groups for alphabets, numbers, animals, and objects ( $\mathrm{P}<0.05$ in each item). The means score of the children in the experimental group showed better development in children's performance than the control group in each item. Moreover, the children in the experimental group had a moderate level of English knowledge in alphabets, animals, and objects; while, they had a high level in numbers. Whereas, the children in the control group still had a low level of English knowledge in alphabets, numbers, animals, and objects, although there was an increase in their score compared to the pre-test, as shown in Table 2. 
Table 2. Mean of pre and post-testing of knowledge level between control and experimental groups

\begin{tabular}{|c|c|c|c|c|}
\hline & \multicolumn{2}{|c|}{ Pre-Test $(n=20)$} & \multicolumn{2}{|c|}{ Post-Test $(n=20)$} \\
\hline & $\begin{array}{c}\text { Control Group } \\
(\mathbf{n}=10) \\
\text { Mean }\end{array}$ & $\begin{array}{c}\text { Experimental } \\
\text { Group }(n=10) \\
\text { Mean }\end{array}$ & $\begin{array}{c}\text { Control Group } \\
(\mathrm{n}=10) \\
\text { Mean }\end{array}$ & $\begin{array}{c}\text { Experimental } \\
\text { Group }(n=10) \\
\text { Mean }\end{array}$ \\
\hline $\begin{array}{l}\text { Alphabet } \\
\text { (Total score }=26 \text { ) }\end{array}$ & 6.6 & 9.8 & 7.4 & 17.4 \\
\hline Paired t-test & \multicolumn{2}{|c|}{$\mathrm{P}=0.3$} & \multicolumn{2}{|c|}{$\mathrm{P}=0.018$} \\
\hline $\begin{array}{l}\text { Number } \\
\text { (Total score }=10)\end{array}$ & 2.1 & 4.0 & 3.2 & 8 \\
\hline Paired t-test & \multicolumn{2}{|c|}{$\mathrm{P}=0.25$} & \multicolumn{2}{|c|}{$\mathrm{P}=0.023$} \\
\hline $\begin{array}{l}\text { Animals } \\
(\text { Total score }=12)\end{array}$ & 3.1 & 3.6 & 3.5 & 8 \\
\hline Paired t-test & \multicolumn{2}{|c|}{$\mathrm{P}=0.7$} & \multicolumn{2}{|c|}{$\mathrm{P}=0.037$} \\
\hline $\begin{array}{l}\text { Objects } \\
(\text { Total score }=19)\end{array}$ & 2.9 & 4.7 & 3.2 & 12.7 \\
\hline Paired t-test & \multicolumn{2}{|c|}{$\mathrm{P}=0.38$} & \multicolumn{2}{|c|}{$\mathrm{P}=0.004$} \\
\hline
\end{tabular}

Note: $P<0.05$ is statistically significant.

Figure 3 shows the overall mean score of the children in both groups. In the control group, the children had a low level of English knowledge in both pre-testing and post-testing. The children in the experimental group changed from a low level in the pre-testing to a moderate post-test level.

Moreover, children in the experimental group were satisfied with the "BenKids" application, and they kept asking to try it again.

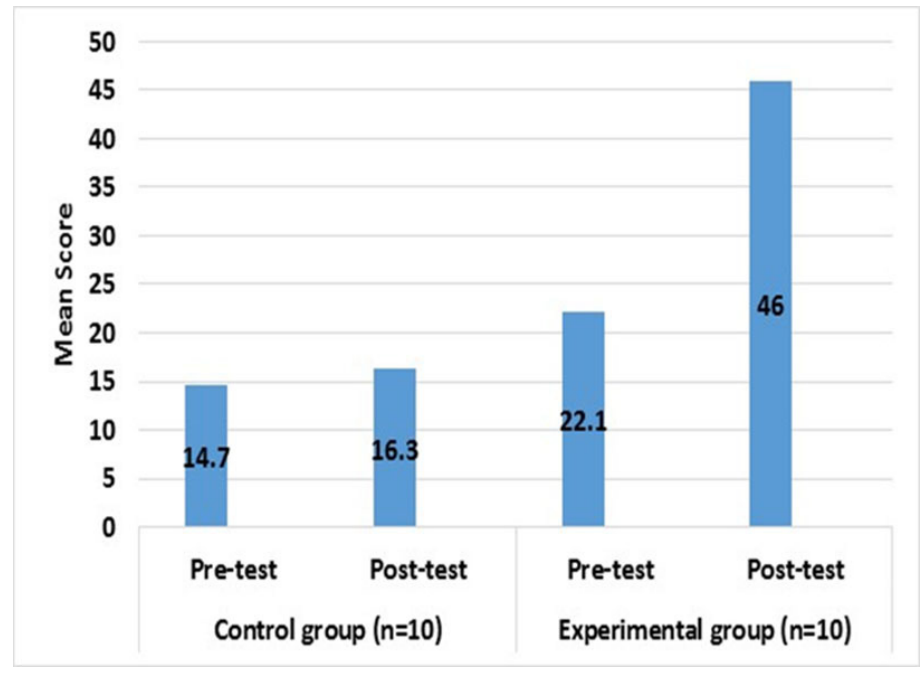

Fig. 3. The overall mean of pre and post-testing 


\subsection{Usability assessment}

The experimental group consisted of 10 preschool children, six boys and four girls. Thirty percent of the experimental group spend about one hour daily using smartphones and tablets, whereas $60 \%$ spend about three hours daily using smartphones and tablets.

The observation checklist based on Jakob Nielsen's four Usability Heuristics Principles was shown in Table 3. Observations showed that the system status is apparent for the preschool children (the experimental group) to help identify where they are at (status) and what to do next (the goal) in the "BenKids" application.

"Match between system and the real world" is to identify if the "BenKids" application buttons are simple enough for the experimental group to understand. Observations showed that the visuals of icons helped children understand the Menu Buttons. Regarding "User control and freedom, Undo keyed input," the experimental group did not find difficulty identifying the Home button. There is another option to go back to the Main Screen. The Exit button is apparent enough for the experimental group to click on it.

"Recognition, Rather than Recall" this section help to identify the Button and Icons. The observation indicated that the experimental group could access the appropriate buttons.

Table 3. Usability heuristics

\begin{tabular}{|c|c|c|}
\hline & Mean & Toward \\
\hline \multicolumn{3}{|l|}{ Visibility of the system status } \\
\hline The child knows which module he/she is currently in, & 2.7 & Good \\
\hline what to do next (the goal) & 2.6 & Good \\
\hline where to go next & 2.6 & Good \\
\hline to go back home. & 2.7 & Good \\
\hline \multicolumn{3}{|l|}{ Match between system and the natural world } \\
\hline Are the menus, buttons, and icons intuitive for the child? & 2.9 & Good \\
\hline Can the child interpret what to do? & 2.8 & Good \\
\hline Is the flow to start and navigate easy? & 2.6 & Good \\
\hline Can the child play with the app without trouble? & 2.6 & Good \\
\hline \multicolumn{3}{|l|}{ User control and freedom, Undo keyed input } \\
\hline Able to click next to continue & 2.6 & Good \\
\hline Able to go back or undo. & 2.7 & Good \\
\hline $\begin{array}{l}\text { Able to go to the main menu and select a different module (in this } \\
\text { case, Alphabet, Word, Sentence). }\end{array}$ & 2.8 & Good \\
\hline Exit from the application. & 2.6 & Good \\
\hline \multicolumn{3}{|l|}{ Recognition rather than recall } \\
\hline $\begin{array}{l}\text { The child knows what to do when they see the menu, button, and } \\
\text { icons. }\end{array}$ & 2.8 & Good \\
\hline How to click a button or icon. & 3 & Good \\
\hline
\end{tabular}

The efficiency of the "BenKids" application is shown in Table 4, the result of three tasks for the "BenKids" application for preschool children (the experimental group, 
$\mathrm{n}=10$ ). The usability test procedure is noted with Complete (C), Incomplete (I), Complete with help $(\mathrm{CH})$, and Complete with Hints/Guide (CG). Most of the experimental group performed Task 1 and Task 2; whereas, 50\% of them could not go back to the alphabet to find the alphabet " $\mathrm{K}$ " in Task 3.

Table 4. Usability Tasks for ten children $(n=10)$. The usability test procedure is noted with Complete (C), Incomplete (I), Complete with help (CH), and Complete with Hints/Guide (CG)

\begin{tabular}{|c|c|c|c|c|}
\hline Test Procedure & $\begin{array}{c}\text { I } \\
\text { No. }(\%)\end{array}$ & $\begin{array}{c}\text { CH } \\
\text { No. }(\%)\end{array}$ & $\begin{array}{c}\text { CG } \\
\text { No. }(\%)\end{array}$ & $\begin{array}{c}\text { C } \\
\text { No. }(\%)\end{array}$ \\
\hline \multicolumn{5}{|l|}{ Task 1} \\
\hline $\begin{array}{l}\text { Open the application and go to Alphabets from } \\
\text { the main menu. }\end{array}$ & $1(10 \%)$ & $1(10 \%)$ & $1(10 \%)$ & $7(70 \%)$ \\
\hline $\begin{array}{l}\text { How can you get the alphabet sound? How can } \\
\text { you repeat the sound? }\end{array}$ & $1(10 \%)$ & $2(20 \%)$ & $0(0 \%)$ & $7(70 \%)$ \\
\hline Go back to the main screen/home & $0(0 \%)$ & $0(0 \%)$ & $3(30 \%)$ & $7(70 \%)$ \\
\hline \multicolumn{5}{|l|}{ Task 2} \\
\hline $\begin{array}{l}\text { Go to the game's menu. Choose the questions } \\
\text { game. }\end{array}$ & $1(10 \%)$ & $1(10 \%)$ & $2(20 \%)$ & $6(60 \%)$ \\
\hline $\begin{array}{l}\text { What do you do on this screen? Listen and } \\
\text { choose the correct picture. }\end{array}$ & $0(0 \%)$ & $1(10 \%)$ & $1(10 \%)$ & $8(80 \%)$ \\
\hline Go back to the previous screen. & $0(0 \%)$ & $0(0 \%)$ & $1(10 \%)$ & $9(90 \%)$ \\
\hline \multicolumn{5}{|l|}{ Task 3} \\
\hline Go back to the Alphabet to find alphabet "K" & $5(50 \%)$ & $0(0 \%)$ & $1(10 \%)$ & $4(40 \%)$ \\
\hline Exit the application & $1(10 \%)$ & $0(0 \%)$ & $2(20 \%)$ & $7(70 \%)$ \\
\hline
\end{tabular}

\section{Discussion}

Several studies have investigated the ability of educational apps to be used for teaching and learning in the educational field, particularly in preschools. The utilization of learning applications plays a vital role in improving the learning environment and facilitating learning. As they have been proven helpful in teaching preschool children, learning applications can help parents help their children learn anywhere they want. The critical goal of incorporating mobile learning into preschool education is to increase young children's interest in learning and increase their knowledge [5][6].

In the pre-test, both the control and the experimental groups had a low level of knowledge in each item (alphabets, numbers, animals, and objects). Nevertheless, the experimental group developed English knowledge after using the "BenKids" application to learn the vocabulary items compared with the control group taught using a traditional style, as shown in Table 2 and Figure 3. This result suggests that children in the experimental group have enhanced knowledge, and they were more involved in learning practice than the children in the control group. Also, the children in the experimental group enjoyed the "BenKids" application, and they wanted to use it again. These are in agreement with many studies [2][15][17]. 
Researchers observed and recorded the children's behavior based on Jakob Nielsen Usability Heuristics Principles, which used four of them. The usability tests were used to identify the efficiency of the app while the children were using it. As gleaned in Table 3, the results showed that the visibility of the system status is apparent for the children to assist in recognizing where they are at (status) and what to try to do next (the goal) within the "BenKids." Most of the children did not find it hard to understand which module they were currently at or the module that they had previously accessed. The Mean score of visibility of the system status was (2.6 of 5), which suggests a usable system in general. Match between the system and the natural world and identify if the "BenKids" application buttons are simple enough to understand. Children aged 3 to 5 years cannot read and thus understand the menu buttons for functional interaction. Therefore, the Main Screen in the "BenKids" app is picture-based. Most of the children find it easy to interact with the main screen and another interface to access the next screen, icons, and images that seem straightforward. They know what to do on every screen.

User control and freedom, undo keyed input, assesses whether the selected "BenKids" allows children to control the tools according to their needs. Most children did not need help or guidance to identify the next, back, and repeat buttons. Two interfaces (color and games) did not have the buttons to go back and go next. There is no Exit button in the Main Menu, so the child uses the tablet's Back button functionality to Exit application.

Recognition rather than recall We desired to see if children can access the appropriate buttons and visually recognize menus, icons, and buttons. A glance at Table 3 shows that the mean is (2.8 and 3), indicating that most children can recognize appropriate buttons such as the repeat and following buttons. The children recognize the next, back, and repeat buttons from the number and alphabet screens. When using the two games, the children recognized their right and wrong answers by either hearing a happy cheer indicating correctness or a buzz indicating wrongness. As gleaned in Table 3, the "BenKids" application is simple and easy to use, and it is understandable. The efficiency of the "BenKids" is shown in Table 4. Most of the children completed Task 1 and Task 2, whereas task 3 was the hardest part.

On the contrary, half of the children could not go back to find the alphabet " $\mathrm{K}$ " in this task. In general, children were satisfied with using "Benkids," but children were not competent enough to moving to specific letters or numbers. Children require training in order to gain the best results when using such applications.

In addition, analyzing the results of knowledge gain and usability, the researchers compared usability and knowledge gain to assess their relationship. This research shows that usability directly relates to learning; that usability has a substantial impact on learning. The high scores obtained in the usability test results show that usability contributes to higher knowledge gain. This finding is in agreement with Sumaira [22]. To enhance learning through educational applications, usability should be handled when implementing this type of apps. 


\section{Conclusion}

This study employs the usability heuristic evaluation method, which has been popular since the early 1990s, to evaluate the usability of mobile learning apps for children. It is a low-cost, effective, and relatively fast usability evaluation method. This study demonstrates that the mobile learning industry should consider usability the most critical issue in developing mobile learning applications. However, when the development proceeds according to the methodology during the project lifecycle to create good-quality mobile educational applications, it ensures learning and motivation, especially with children. Children use more smartphones through their parents, and some schools adopt the technology. Using smart mobile devices among elementary school students and children has also increased exponentially. It is said that the ease of use, portability, speed, and responsiveness of smart mobile devices make them ideal learning tools [23][24][25]. The purpose of this research was to assess knowledge gain, and the purpose of the usability test of the "BenKids" mobile app was to accept and use it in education. While it was found in this research that there was a strong relationship between knowledge gain and usability, where usability has a substantial impact on knowledge gain, to make educational apps effective for learning and increase the progress in education, the focus should be on usability. The children need to be trained on the application to use it and benefit from it effectively.

\section{Limitations}

Some limitations faced the study. First, most kindergartens in Benghazi focus on teaching Arabic and mathematics. Also, some kindergartens did not accept participation because they thought the study took a long time. All these led to the small size of the study sample. Therefore, the researchers believe that the study should be repeated shortly with a large sample from many kindergartens to establish the usability and learning benefits of the app. In addition, most children do not own smartphones or tablets, which forced researchers to provide the devices during the study period. Although the results were acceptable, the researchers believed that some of the difficulties the children faced with the "BenKids" application may be due to the children's use during the class only.

\section{Acknowledgments}

The authors would like to express their gratitude to Daar Alallam preschool, all the children, and parents who made this study possible.

\section{Declaration of conflicting interests}

The authors declared that they had no conflicts of interest concerning their authorship or the publication of this article. 


\section{References}

[1] H. Guo, "Analysing and Evaluating Current Mobile Applications for Learning English Speaking," University of London, 2013.

[2] S. Kilis, "Impacts of Mobile Learning in Motivation, Engagement and Achievement of Learners: Review of Literature," Gaziantep Univ. J. Soc. Sci., vol. 12, no. 2, pp. 375-383, 2013 [Online]. Available: http://jss.gantep.edu.tr

[3] M. Masood and M. Thigambaram, "The Usability of Mobile Applications for Pre-schoolers," Procedia - Soc. Behav. Sci., vol. 197, no. February, pp. 1818-1826, 2015, doi: https://doi. org/10.1016/j.sbspro.2015.07.241

[4] G. K. Kokkalia and A. S. Drigas, “Mobile Learning for Special Preschool Education,” Int. J. Interact. Mob. Technol., vol. 10, no. 1, pp. 60-67, 2016, doi: https://doi.org/10.3991/ijim. v10i1.5288

[5] N. Bukharaev and A. W. Altaher, "Mobile Learning Education has Become More Accessible," Am. J. Comput. Sci. Inf. Technol., vol. 5, pp. 3-7, 2017, doi: https://doi. org/10.21767/2349-3917.100005

[6] P. Dorouka, S. Papadakis, and M. Kalogiannakis, "Nanotechnology and Mobile Learning: Perspectives and Opportunities in Young Children's Education," International Journal of Technology Enhanced Learning, vol. 13, no. 3, pp. 237-252, 2021. https://doi.org/10.1504/ IJTEL.2021.115975

[7] K. Ellingson, "Interactive Technology Use in Early Childhood Programs to Enhance Literacy Development \& Early Literacy Development for Children with Cochlear Implants," p. 3, 2016.

[8] E. Wood, M. Petkovski, D. De Pasquale, A. Gottardo, M. A. Evans, and R. S. Savage, "Parent Scaffolding of Young Children When Engaged With Mobile Technology," Front. Psychol., vol. 7, no. MAY, pp. 1-11, 2016, doi: https://doi.org/10.3389/fpsyg.2016.00690

[9] J. Vaiopoulou, S. Papadakis, E. Sifaki, D. Stamovlasis, and M. Kalogiannakis, "Parents' Perceptions of Educational Apps Use for Kindergarten Children: Development and Validation of a New Instrument (PEAU-p) and Exploration of Parents' Profiles," Behavioral Sciences, vol. 11, no. 6, p. 82, 2021. https://doi.org/10.3390/bs11060082

[10] S. Papadakis, "The Impact of Coding Apps to Support Young Children in Computational Thinking and Computational Fluency. A Literature Review," Front. Educ., vol. 6, no. June, pp. 1-12, 2021, doi: https://doi.org/10.3389/feduc.2021.657895

[11] S. Papadakis, M. Kalogiannakis, and N. Zaranis, "Teaching Mathematics With Mobile Devices and the Realistic Mathematical Education (RME) Approach in Kindergarten," Adv. Mob. Learn. Educ. Res., vol. 1, no. 1, pp. 5-18, 2021, doi: https://doi.org/10.25082/ AMLER.2021.01.002

[12] C. Shuler, "iLearn'II: An Analysis of the Education Category of Apple's App Store,” 2012.

[13] A. N. Idres, S. Eltalhi, R. Imsallim, and H. Kutrani, "Mobile Learning Application Development for Learning English to Preschool Students," Int. J. Sci. Res., vol. 8, no. 12, pp. 631-634, 2019, doi: 10.21275/ART20202825

[14] M. Ampartzaki, M. Kalogiannakis, and S. Papadakis, "Deepening Our Knowledge about Sustainability Education in the Early Years: Lessons from a Water Project," Education Sciences, vol. 11, no. 6, p. 251, 2021. https://doi.org/10.3390/educsci11060251

[15] M. Taibah, "Usability Survey of Educational Software Used by Children at Schools," J. Mason Grad. Res., vol. 3, no. 1, pp. 22-39, 2016.

[16] M. Niranjanamurthy, A. Nagaraj, H. Gattu, and P. K. Shetty, "Research Study on Importance of Usability Testing / User Experience ( UX ) Testing," Int. J. Comput. Sci. Mob. Comput., vol. 3, no. 10, pp. 78-85, 2014. 
[17] H. Schelhowe, H. Rantel, and L. De Araujo, "Usability Testing With Children: BatiKids Case Study," Int. J. Educ. Pedagog. Sci., vol. 10, no. 10, pp. 3500-3504, 2016.

[18] H. M. Haggag, "Teaching Phonetics Using A Mobile-Based Application in an EFL Context," Eur. Sci. Journal, ESJ, vol. 14, no. 14, pp. 189-204, 2018, doi: https://doi.org/10.19044/ esj.2018.v14n14p189

[19] J. A. Cuevas, A. Education, and N. Georgia, "Mobile Learning and its Effects on Academic Achievement and Student Motivation in Middle Grades Students," Int. J. Scholarsh. Technol. Enhanced. Learn., vol. 1, no. 2, pp. 91-110, 2017.

[20] A. M. Sari and H. Nurcahyo, "Improving Students Learning Motivation Through Mobile Learning,” J. Pendidik. Biol. Indones., vol. 4, no. 3, pp. 271-276, 2018, doi: https://doi. org/10.22219/jpbi.v4i3.6859

[21] J. Nielsen, “10-Heuristics-for-User-Interface-Design.” Retrieved from https://www. nngroup.com/articles/ten-usability-heuristics/\#contentBody

[22] S. Shafiq and T. A. Khan, "Role \& Value of Usability in Educational Learning via Game Based Apps," Int. J. Sci. Technol. Res., vol. 7, no. 11, pp. 70-77, 2018.

[23] S. Papadakis and M. Kalogiannakis, "Evaluation of Greek Android mobile applications for preschoolers," Preschool and Primary Education, vol. 5, pp. 65-100, 2017. https://doi. org/10.12681/ppej.11208

[24] N. Vidakis, A. K. Barianos, A. M. Trampas, S. Papadakis, M. Kalogiannakis, and K. Vassilakis, "In-Game Raw Data Collection and Visualization in the Context of the "ThimelEdu" Educational Game," In Lane H.C., Zvacek S., Uhomoibhi J. (eds) Computer Supported Education. CSEDU 2019. Communications in Computer and Information Science, vol. 1220. Springer, Cham, (2020). https://doi.org/10.1007/978-3-030-58459-7 30

[25] S. Papadakis, "Advances in Mobile Learning Educational Research (AMLER): Mobile learning as an educational reform," Advances in Mobile Learning Educational Research, vol. 1, no. 1, pp. 1-4, 2021. https://doi.org/10.25082/AMLER.2021.01.001

\section{Authors}

Saria Eltalhi is a Lecturer at Department of Computer Science Studies at Faculty of Information Technology, University of Benghazi. Her research revolves around Mobile apps, Machine Learning and Data Mining.

Huda Kutrani is assistant professor at Health Informatics Department, Faculty of Public Health, University of Benghazi; Benghazi, Libya

Reem Imsallim Graduate Studies, Benghazi. Publishing consultant with Mediterranean Sea University Magazine. The author has an MA in English language teaching and is a lecturer at the English Department at the Faculty of Education Benghazi.

Mikael Elrefady Professor of Educational Research Methods and Applied Statistics, Department of Educational Planning and Administration, Faculty of Arts, University of Benghazi. Head of the Department of Educational Administration, Academy of Graduate Studies, Benghazi. Publishing consultant with Mediterranean Sea University Magazine.

Article submitted 2021-02-22. Resubmitted 2021-08-21. Final acceptance 2021-08-21. Final version published as submitted by the authors. 